\title{
Tactual recognition of embossed Morse code, letters, and braille
}

\author{
MORTON A. HELLER, KIMBERLY D. NESBITT, \\ DANETTE K. SCROFANO, and DENELL DANIEL \\ Winston-Salem State University, Winston-Salem, North Carolina
}

\begin{abstract}
A series of experiments was performed to evaluate the relative utility of embossed codes. Blindfolded sighted subjects attempted tactual recognition of braille, printed capital letters, and an embossed Morse code. Accuracy was generally similar for large embossed printed letters and braille. However, Morse code required much longer exploration times than did the other symbols.
\end{abstract}

Written communication is of clear importance to blind persons, yet relatively little is known about the factors that enhance tactual pattern recognition. Reading braille is much slower than visual reading of print (Foulke, 1982). Many blind persons seem to find reading braille extremely difficult, whether reading braille very slowly, or not learning it at all. Consequently, a large number of late-blind individuals are without any form of written communication. Many congenitally blind persons may know braille, even if they have not been taught to write their names in script or print or have had little or no experience with raised-line drawing kits. Blind persons can certainly learn to make sense of pictures produced with raised lines (Heller, 1989; Kennedy, 1982), and, after instruction, many are able to use maps and other tangible displays well (Berla, 1982).

In numerous papers, Loomis (1981a, 1981b, 1982, 1985) has argued that touch is limited in its ability to resolve fine spatial detail. He reported that braille was superior to embossed print, and that blurred vision was comparable to touch for pattern identification. Loomis (1981a) found only about $80 \%$ correct performance for tactual examination of 9-mm high embossed print letters. In a more recent study (1985), Loomis found even lower performance (less than $43 \%$ correct) for 5.7-mm letters. This is considerably lower than what other researchers have reported for larger patterns (Austin \& Sleight, 1952; Barr, 1970; Seminara, 1960). Loomis (1981a) restricted tactile scanning, both temporally (1-2 sec per symbol) and spatially, which may have lowered performance. It should be noted that tactile $2 \mathrm{D}$ pattern recognition is normally much slower than visual identification (Heller, 1984). Loomis limited the ability of his subjects to move their fingertips as they touched patterns. They were constrained

This work was supported by NIH MBRS Grant 2 SO6 RR-08040. We wish to thank Emerson Foulke for the loan of the special slate that was used to generate the stimuli in the second experiment. We also wish to thank Faith Heller for her comments on an earlier version of this manuscript. Correspondence may be addressed to Morton A. Heller, Department of Psychology, Winston-Salem State University, WinstonSalem, NC 27110 . to make simple rotary motions and were not allowed to obtain sequential input through scanning or tracing with the fingertip. Movement of the fingertip can certainly aid pattern recognition (Heller 1986; Heller, Scrofano, \& Nesbitt, 1989). The present experiments attempted a further comparison of braille and other tangible symbols, but with more naturalistic circumstances-that is, with relatively unrestricted exploration.

The present study was designed to evaluate several embossed tangible codes. In Experiments 1 and 2, braille and embossed printed letters were compared. Experiment 3 involved a comparison of embossed printed letters, braille, and embossed Morse code.

\section{EXPERIMENTS 1 AND 2 \\ Printed Letters and Braille}

The subjects in the first two experiments attempted visual matches to braille or named embossed capital letters. It was not known whether braille would have any advantage, given free exploration.

\section{Method}

Subjects. Two groups of subjects $(N=20 ; 10$ males and 10 females $)$ examined the 8-mm patterns in Experiment 1; all observers in the present experiments were sighted. Experiment 2, with $11-\mathrm{mm}$ characters, involved 12 undergraduate students (6 males and 6 females).

Stimuli and Apparatus. The stimuli in Experiment 1 consisted of the embossed, printed capital letters A, H, I, M, O, T, U, V, X, and $\mathrm{W}$, along with corresponding (jumbo) braille characters. The braille was approximately $8 \mathrm{~mm}$ high, embossed with a Perkins brailler. The 8-mm-high letters were embossed on standard braille paper with a Freund writing screen and braille stylus (produced by the American Foundation for the Blind). Contiguous dots made up the print letter shapes that were first traced by a Koh-I-Noor (Rapidoguide) letter guide. The stimuli in Experiment 2 consisted of 11-mm-high capital letters ( $K$ through T) and corresponding braille characters. This giant braille was produced with a special $6 \times 6$ (dots) slate provided by Emerson Foulke. Stimuli were constructed by using dot positions within a $5 \times 5$ matrix. The vertical and horizontal spacing between braille dots was about $3 \mathrm{~mm}$. For embossed print letters, the spacing between dots was usually minimal-less than $1 \mathrm{~mm}$. Standard American braille is less than $6 \mathrm{~mm}$ high (Heller, 1987).

The stimuli were placed on a foam-covered shelf behind a large baffle with a cloth-covered opening at its base. This device allowed observers to touch the stimuli without vision. A drawing of the braille code and letter equivalents (as appropriate) was present during tactual ex- 
Table 1

Tactual Examination of Braille and Letters: Mean Number Correct and Time per Item (in Seconds)

\begin{tabular}{|c|c|c|c|c|c|c|c|c|}
\hline \multirow{4}{*}{$\begin{array}{c}\text { Character } \\
\text { Type }\end{array}$} & \multicolumn{8}{|c|}{ Character Size } \\
\hline & \multicolumn{4}{|c|}{$11 \mathrm{~mm}$} & \multicolumn{4}{|c|}{$8 \mathrm{~mm}$} \\
\hline & \multicolumn{2}{|c|}{$\begin{array}{l}\text { Number } \\
\text { Correct }\end{array}$} & \multicolumn{2}{|c|}{ Time } & \multicolumn{2}{|c|}{$\begin{array}{l}\text { Number } \\
\text { Correct } \\
\end{array}$} & \multicolumn{2}{|c|}{ Time } \\
\hline & $M$ & $S D$ & $M$ & $S D$ & $M$ & $S D$ & $M$ & $S D$ \\
\hline Braille & 33.9 & 7.2 & 11.6 & 3.9 & 25.6 & 3.3 & 7.3 & 4 \\
\hline Letters & 37.0 & 2.4 & 9.4 & 3.9 & 25.9 & 2.6 & 9.2 & 6.6 \\
\hline
\end{tabular}

Note-The maximum possible scores $=40$ and 30 correct, for $11-\mathrm{mm}$ and $8-\mathrm{mm}$ characters, respectively.

amination of the stimuli. For Experiment 1, the 10 letters were presented three times each in a random arrangement. Characters were arrayed in five horizontal lines with 6 stimuli on each line. The stimuli were separated by $1.4 \mathrm{~cm}$, with a vertical spacing between lines of about $1.8 \mathrm{~cm}$. In Experiment 2, the 10 characters were presented four times each in a random arrangement in four horizontal lines.

Design and Procedure. Experiment 1 involved independent groups, whereas observations were repeated on subjects in Experiment 2. In Experiment 2 , half of the subjects started with braille and then explored letters; half of them followed the reverse sequence. The subjects touched the stimuli with the tip of the index finger of the preferred (writing) hand and named the letter corresponding to the character that was touched. The subjects were timed on each line of letters or braille (with a stopwatch). No feedback was given when the subjects tried to name the upright patterns. The subjects were told to press lightly as they explored the stimuli.

\section{Results and Discussion}

Recognition accuracy was similar for letters and braille (see Table 1). The 8 -mm letters $(86 \%$ correct) were not significantly different from 8-mm braille in ease of identification $(85 \% ; t<1)$. Performance was comparable for larger letters $(92.5 \%)$ and braille $[85 \% ; t(11)=1.5$, $p>.05]$. The high levels of accuracy in Experiment 2 are consistent with reports of excellent performance with much larger letters (Barr, 1970; Seminara, 1960). Response latency was not significantly faster for 8-mm braille $(M=7.3 \mathrm{sec} /$ item $)$ than for letters $(M=9.3 \mathrm{sec}$; $t<1)$. The comparison of larger letters $(M=9.4 \mathrm{sec})$ and 11-mm braille $(M=11.6 \mathrm{sec})$ approached significance $[t(11)=2.09, p<.10>.05]$.

The letter recognition data obtained in Experiments 1 and 2 are inconsistent with prior reports of the general superiority of braille over letters. Loomis (1985) found better accuracy for braille, probably due to both the small character size he employed and the imposition of constraints on exploration. With free exploration, larger letters are as easy to recognize, and are certainly identified as rapidly, as braille. Tactual letter recognition can approach $100 \%$ with large enough patterns (Austin \& Sleight, 1952; Seminara, 1960) and sufficient practice (Barr, 1970).

\section{EXPERIMENT 3}

\section{Braille, Letters, and Morse Code}

In Experiment 3, we compared Morse code, braille, and embossed, printed capital letters in recognition accuracy and latency.

\section{Method}

Subjects. There were 36 sighted undergraduate subjects in the present experiment.

Stimuli and Apparatus. The stimuli were embossed characters representing the letters A-J. Prior research has shown very low accuracy levels when Morse code was embossed on index cards with a nonelectric typewriter (Heller, 1985). This low performance may have been due to poorly prepared stimuli (the dots and dashes were not very high), rather than deficiencies in the code itself. Consequently, the Morse code and other stimuli were embossed on label tape with a $3 \mathrm{M}$ labeler. The symbols were presented five times each in a random arrangement; they were arrayed in horizontal lines with approximately $1.6 \mathrm{~cm}$ between characters and $1.3 \mathrm{~cm}$ between lines. The braille was of standard size (6 $\mathrm{mm}$ high; the characters A-J are less than $4 \mathrm{~mm}$ ), produced with a Scotch 3M EA-450 Labeler (with a braille dial) on clear labeling tape. The embossed capital letters were roughly $5 \mathrm{~mm}$ high; the same spacing was used. The Morse code was drawn from the current International Morse code (Spragg, 1943; Taylor, 1943): A $(\cdot-)$, B $(-\cdots)$, $\mathrm{C}(-\cdot-\cdot), \mathrm{D}(-\cdot)), \mathrm{E}(\cdot), \mathrm{F}(\cdot-\cdot), \mathrm{G}(--\cdot), \mathrm{H}(\cdot \cdots), \mathrm{I}(\cdot)$, and $\mathrm{J}(\cdot---)$. The dashes were slightly lower $(1 \mathrm{~mm})$ on each line than the dots. Though shorter than the other patterns, the Morse code was generally much wider; the largest character was $1.9 \mathrm{~cm}$ wide.

Design and Procedure. The procedure, similar to that of Experiment 1 , involved independent groups. All subjects were shown the characters representing the letters A-J prior to stimulation; a drawing of the braille or Morse code (as appropriate) was present throughout. The subjects were told the layout of the symbols and were also informed they would be timed with a stopwatch; feedback was not given. The subjects were restricted to the tip of the index finger of the preferred hand, as in the first two experiments.

\section{Results and Discussion}

Braille recognition accuracy was not significantly different from that for printed letters or Morse code $[F(2,33)=$ $2.2, p>.05]$. However, an analysis of variance on time scores showed a significant effect of the code used $[F(2,33)=9.8, p<.001]$. Though not more difficult, Morse code was much slower than the other codes (see Table 2). A Newman-Keuls test on mean total time showed that braille and printed letters required the same exploration time $(p>.05)$, but both were faster than Morse code $(p<.01)$. The obtained accuracy with small letters ( $5 \mathrm{~mm}, 57.6 \%$ correct) was very close to Phillips, Johnson, and Browne's (1983) report of $60 \%$ correct for 4.5-mm letters.

Morse code performance was much better in the present Experiment 3 than had been found previously (Heller, 1985). This advantage is probably a consequence of the use of more tangible stimuli, with lines and dots of greater height and durability.

\section{GENERAL DISCUSSION}

Performance was similar for embossed print capital letters and braille in Experiments 1, 2, and 3. Embossed letters (11 mm) yielded $92.5 \%$ correct recognition in Experiment 2-a very high level of performance for naive observers. Recognition accuracy was nearly as high for Morse code as for braille, but the reading of the system of embossed dots and dashes was much slower in Experiment 3.

The results of the present experiments are not consistent with the idea that braille is invariably superior to tangible print. The functional spatial abilities of the finger are sometimes limited by spatial resolution when observers are confronted by very small stimuli and exploration is constrained, both temporally and spatially. The use of relatively large patterns and unrestricted tactual exploration can serve to eliminate the advantages of braille, at least for recognition of single characters. Of course, it is not known if large embossed letters are equally suitable 
Table 2

Experiment 3: Braille, Letters, and Morse Code

\begin{tabular}{lccccc}
\hline & \multicolumn{2}{c}{$\begin{array}{c}\text { Number } \\
\text { Character } \\
\text { Type }\end{array}$} & & \multicolumn{2}{c}{$\begin{array}{c}\text { Exploration } \\
\text { Time }\end{array}$} \\
\cline { 2 - 3 } \cline { 5 - 6 } & $M$ & $S D$ & & $M$ & $S D$ \\
\hline Braille & 33.3 & 8.4 & & 422.3 & 149.8 \\
Morse code & 26.1 & 8.9 & & 796.0 & 290.1 \\
Letters & 28.8 & 8.3 & & 485.1 & 201.3 \\
\hline
\end{tabular}

Note-The maximum score possible $=50$ correct. Exploration time is given in seconds.

for written communication when words are involved, though history tells us that reading print words is much slower than reading braille (Foulke, 1982). Reading slowly, however, is preferable to not reading at all. Future research will need to be directed toward an understanding of more naturalistic reading behavior. The high levels of recognition accuracy that were found for embossed print letters are consistent with the reports of other researchers (Austin \& Sleight, 1952; Seminara, 1960).

Large embossed print letters are easy to recognize with touch, which has implications for the rehabilitation of the late blind. Many of these persons have had considerable difficulty learning braille. The present results suggest that people who are unwilling to learn braille might be encouraged to make use of embossed print letters instead. The late blind could make use of a Swedish raised-line drawing kit for writing (see Heller, 1989). It is proposed that the letters should be at least 8-11 mm high, since lower recognition accuracy was found for smaller patterns $(5 \mathrm{~mm})$ in Experiment 3 . The early blind do not have the same difficulty with braille, since their education in braille reading extends over a long period of time in childhood.

\section{REFERENCES}

Austin, T. R., \& SLEIGHT, R. B. (1952). Accuracy of tactual discrimination of letters, numerals, and geometric forms. Journal of Experimental Psychology, 43, 239-247.

BARR, R. L. (1970). Embossing Arabic letters and numbers on new raised-line polyethylene paper: An aid for the blind. Science, 169, 94-95.

BERLA, E. P. (1982). Haptic perception of tangible displays. In W. Schiff
\& E. Foulke (Eds.), Tactual perception: A sourcebook (pp. 364-386). New York: Cambridge University Press.

FoulKe, E. (1982). Reading braille. In W. Schiff \& E. Foulke (Eds.), Tactual perception: A sourcebook (pp. 168-208). New York: Cambridge University Press.

Heller, M. A. (1984). Active and passive touch: The influence of exploration time on form recognition. Journal of General Psychology, 110, 243-249.

Heller, M. A. (1985). Tactual perception of embossed Morse code and braille: The alliance of vision and touch. Perception, 14, 563-570.

Heller, M. A. (1986). Active and passive tactile braille recognition. Bulletin of the Psychonomic Society, 24, 201-202.

Heller, M. A. (1987). The effect of orientation on visual and tactual braille recognition. Perception, 16, 291-298.

Heller, M. A. (1989). Picture and pattern perception in the sighted and blind: The advantage of the late blind. Perception, 18, 379-389.

Heller, M. A., Scrofano, D. K., \& Nesbitt, K. D. (1989). Effect of tactual scanning mode on braille and shape recognition. Bulletin of the Psychonomic Society, 27, 131-132.

KenNedY, J. M. (1982). Haptic pictures. In W. Schiff \& E. Foulke (Eds.), Tactual perception: A sourcebook (pp. 305-333). New York: Cambridge University Press.

Loomis, J. M. (1981a). On the tangibility of letters and braille. Perception \& Psychophysics, 29, 37-46.

LoOMIs, J. M. (1981b). Tactile pattern perception. Perception, 10, 5-27.

Loomis, J. M. (1982). Analysis of tactile and visual confusion matrices. Perception \& Psychophysics, 31, 41-52.

Loomis, J. M. (1985). Tactile recognition of raised characters: A parametric study. Bulletin of the Psychonomic Society, 23, 18-20.

MAGEE, L. E., \& KENNEDY, J. M. (1980). Exploring pictures tactually. Nature, 283, 287-288.

Phillips, J. R., Johnson, K. O., \& Browne, H. M. (1983). A comparison of visual and two modes of tactual letter resolution. Perception \& Psychophysics, 34, 243-249.

Seminara, J. L. (1960). Accuracy and speed of tactual reading: An exploratory study. Ergonomics, 3, 62-67.

SPRAGG, S. D. S. (1943). The relative difficulty of Morse code alphabet characters learned by the whole method. Journal of Experimental Psychology, 33, 108-114.

TAYLOR, D. W. (1943). Learning telegraphic code. Psychological Bulletin, 40, 461-487.

(Manuscript received July 1, 1989.) 